\title{
TUGAS PAKET PROGRAM STATISTIK
}

Harga Lisensi Software:

- EViews

- Minitab

- SPSS

- STATA

- Mplus

- SAS

Per tahun

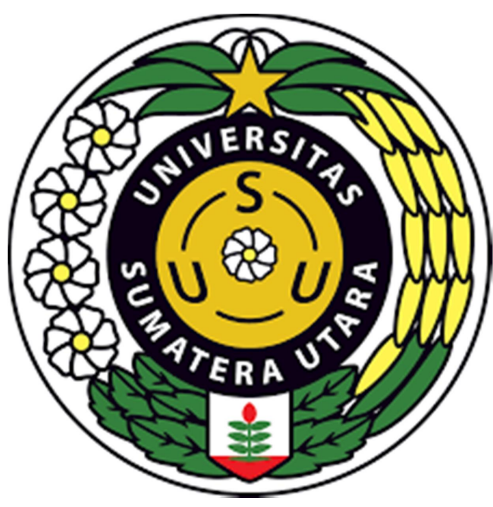

Disusun oleh:

1. Josua Silalahi

(182407014)

2. Jessica Adelina Sinaga

(182407016)

3. Claudia Christati Masniari Pasaribu

4. Sabarita Br Tarigan

5. Muhamad Isnaldy

6. Sardo Septima Lia Simbolon

Program Studi D3 Statistika

Fakultas Matematika dan Ilmu Pengetahuan Alam Universitas Sumatera Utara 
Harga lisensi software

1. EViews

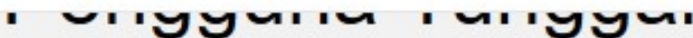

Semua Lisensi Pengguna Tunggal dari EViews 11 dilengkapi dengan dokumentasi lengkap yang disediakan dalam format PDF, termasuk EViews Illustrated oleh Richard Start. Setelah EViews 11 dibeli, Anda akan dikirimi email dengan nomor seri dan tautan untuk mengunduh pemasang EViews 11.

Anda dapat memasukkan salah satu opsi pelatihan kami sebagai bagian dari pembelian Anda. Semua paket pelatihan (termasuk webinar) akan menerima diskon 20\% ketika dibeli dengan lisensi baru EViews.

Perhatikan bahwa versi Pengguna Tunggal EViews 11 dapat dibeli secara online dengan mengklik tautan di bawah ini, atau mengunjungi toko web EViews. Semua produk EViews lainnya harus dibeli dengan menqhubunqi kantor kami.

\begin{tabular}{|l|c|c|}
\hline \multicolumn{1}{|c|}{ Komersial - Lisensi Baru } & $\begin{array}{c}\text { Standar } \\
\text { EV11 }\end{array}$ & $\begin{array}{c}\text { Perusahaan } \\
\text { EV11 }\end{array}$ \\
\hline Lisensi Pengguna Tunggal & $\underline{\$ 1.650}$ & $\underline{\$ 1.995}$ \\
\hline \multicolumn{1}{|c|}{ Komersial - Tingkatkan Lisensi } & $\begin{array}{c}\text { Standar } \\
\text { EV11 }\end{array}$ & $\begin{array}{c}\text { Perusahaan } \\
\text { EV11 }\end{array}$ \\
\hline Upgrade dari EViews 11 Standard & $\underline{\mathrm{NA}}$ & $\underline{\$ 650}$ \\
\hline *Tingkatkan dari EViews 1 - 10 Edisi Standar & $\underline{\$ 700}$ & $\underline{\$ 1.075}$ \\
\hline *Tingkatkan dari EViews 1 - 10 Edisi Perusahaan & $\underline{\mathrm{NA}}$ & $\$ 850$ \\
\hline
\end{tabular}

\section{Academic EViews 11 Harga Pengguna Tunggal ${ }^{1}$}

\begin{tabular}{|l|l|}
\hline \multicolumn{1}{|c|}{ Akademik - Lisensi Baru } & $\begin{array}{c}\text { Perusahaan } \\
\text { EV11 }\end{array}$ \\
\hline Lisensi Penguna Tunggal & $\$ 590$ \\
\hline \multicolumn{1}{|c|}{ Akademik - Tingkatkan Lisensi } & $\begin{array}{c}\text { Perusahaan } \\
\text { EV11 }\end{array}$ \\
\hline $\begin{array}{l}\text { Tingkatkan dari EViews 1 - EViews 10 Edisi Standar atau } \\
\text { Edisi Perusahaan }\end{array}$ & $\$ 330$ \\
\hline
\end{tabular}

Agar memenuhi syarat untuk penetapan harga Lisensi Akademik Penqquna Tunqqal , penerima lisensi harus berafiliasi dengan lembaga yang terakreditasi dan pemberi gelar. Fakultas dan mahasiswa lembaga akademik harus memberikan bukti terkini mengenai afiliasi akademik. 
Berdasarkan data yang telah kami cari pada lisensi software EViews,besar biaya Lisensi software ini pertahun berbeda-beda untuk setiap Versi atau Kebutuhan penggunanya,Misalnya untuk Tunggal,harga yang ditawarkan relatif lebih murah dibandingkan dengan penggunaan Perusahaan.Perhatikan Gambar diatas.

Link: https://www.eviews.com/general/prices/prices.html

2. Minitab

\section{Full Version, Single-User License}

\begin{tabular}{|c|c|c|}
\hline $\begin{array}{l}\text { Analyze your data and improve your products } \\
\text { and services with the leading statistical software }\end{array}$ & Operating System & Windows (64-bit) \\
\hline $\begin{array}{l}\text { used to implement quality improvement } \\
\text { worldwide. }\end{array}$ & Quantity & $1:$ \\
\hline Volume discount pricing is applied in the cart. & Unit price & IDR 28,273,687 \\
\hline
\end{tabular}

\section{Upgrade Version, Single-User License}

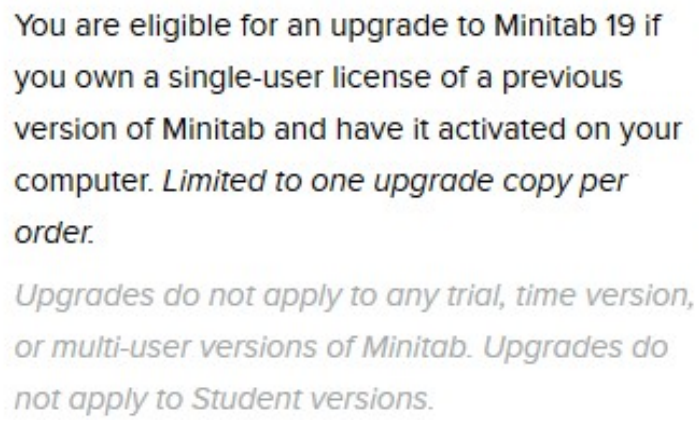

Link: https://www.minitab.com/en-us/products/minitab/pricing/ 


\section{SPSS}

\section{Base Subscription}

- Monthly and annual subscription plans available

- Desktop edition available on Windows and Mac

- A variety of statistical procedures such as factor analysis, clustering and linear regression

STARTING AT

$\$ 99.00$ USD $^{\star}$

per user per month
- Advanced data preparation and bootstrapping capabilities

- A wide range of reporting and export options including Microsoft/PDF

- Syntax and open source programming

Purchase now

$\rightarrow$ Try for free (includes add-ons)

Harga lisensi SPSS perbulan $\$ 99.00$ USD

Harga lisensi SPSS pertahun $\$ 99.00 \times 12=\$ 1188$ USD

Link:https://www.ibm.com/products/spss-

statistics/pricing? mhsrc=ibmsearch a\&mhq=IBM\%20SPSS\%20Statistics/

\section{STATA}

Renewal purchases

Business single-user

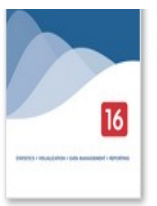

\begin{tabular}{|c|c|c|c|c|}
\hline Stata/IC & Stata/SE & Stata/MP 0 & Stata/MP & Stata/MP \\
For mid-sized datasets. & For large datasets. & $\begin{array}{c}\text { 2-core } \\
\text { Faster \& for the largest datasets. }\end{array}$ & $\begin{array}{c}\text { 4-core } \\
\text { Even faster. }\end{array}$ & $>4$ cores \\
$\begin{array}{c}\text { \$595 USD } \\
\text { per year }\end{array}$ & $\begin{array}{c}\text { \$765 USD } \\
\text { per year }\end{array}$ & $\begin{array}{c}\text { \$895 USD } \\
\text { per year }\end{array}$ & $\begin{array}{c}\text { \$995 USD } \\
\text { per year }\end{array}$ & $\begin{array}{c}\text { \$2,795 USD } \\
\text { per year }\end{array}$ \\
\hline Buy & Buy & Buy & Buy & Buy \\
\hline
\end{tabular}


Renewal purchases

Government/nonprofit single-user

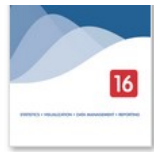

\begin{tabular}{|c|c|c|c|c|}
\hline $\begin{array}{c}\text { Stata/IC } \\
\text { For mid-sized datasets. }\end{array}$ & $\begin{array}{c}\text { Stata/SE } \\
\text { For large datasets. }\end{array}$ & $\begin{array}{c}\text { Stata/MP } 0 \\
2 \text {-core } \\
\text { Faster \& for the largest datasets. }\end{array}$ & $\begin{array}{l}\text { Stata/MP } \\
\text { 4-core } \\
\text { Even faster. }\end{array}$ & $\begin{array}{l}\text { Stata/MP } \\
>4 \text { cores } \\
\text { Faster still. }\end{array}$ \\
\hline & & & & $\begin{array}{|ll|}\text { 64-cores } \quad \checkmark \\
\end{array}$ \\
\hline$\underset{\text { per year }}{\$ 595 \text { USD }}$ & $\underset{\text { per year }}{\$ 765 \text { USD }}$ & $\underset{\text { per year }}{\$ 895 \text { USD }}$ & $\begin{array}{c}\text { \$995 USD } \\
\text { per year }\end{array}$ & $\underset{\substack{\text { per year } \\
\$ 2,795 \text { USD }}}{ }$ \\
\hline Buy & Buy & Buy & Buy & Buy \\
\hline
\end{tabular}

Renewal purchases

Stata Campus GradPlan ${ }^{\text {Th }}$

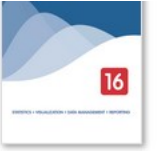

\begin{tabular}{|c|c|c|c|}
\hline Stata/IC & Stata/SE & Stata/MP o & Stata/MP \\
\hline & & 2-core & 4-core \\
\hline For mid-sized datasets. & For large datasets. & Faster \& for the largest datasets. & Even faster. \\
\hline$\underset{\text { per year }}{\$ 125 \text { USD }}$ & $\underset{\text { per year }}{\$ 195 \text { USD }}$ & $\underset{\text { per year }}{\text { \$295 USD }}$ & $\begin{array}{c}\$ 425 \text { USD } \\
\text { per year }\end{array}$ \\
\hline Buy & Buy & Buy & Buy \\
\hline
\end{tabular}

\section{Student pricing}

Students currently enrolled at degree-granting institutions may purchase Stata at the prices listed below. Proof of student status (i.e., copy of your university ID card) is required.

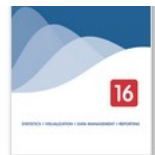

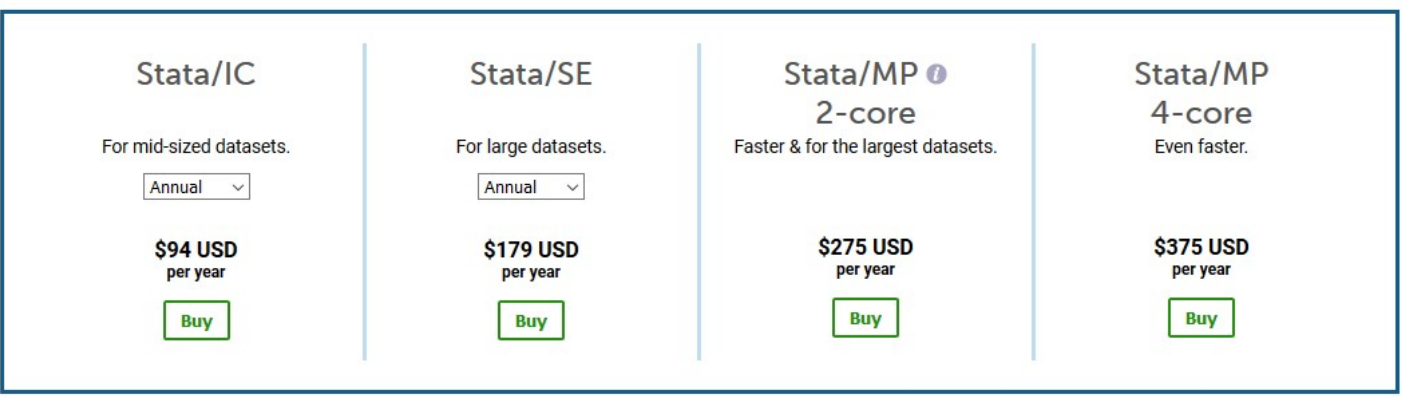

Link: https://www.stata.com/order/new/bus/renewal/ 
5. Mplus

Mplus Version 8.3 University Pricing

\begin{tabular}{l|c}
\hline Mplus Version 8.3 Products & $\begin{array}{c}\text { Version 8.3 Pricing For New } \\
\text { Licencees }\end{array}$ \\
\hline Mplus Base Program & $\$ 595$ \\
\hline Mplus Base Program and Mixture Add-On & $\$ 745$ \\
\hline Mplus Base Program and Multilevel Add-On & $\$ 745$ \\
\hline Mplus Base Program and Combination Add-On & $\$ 895$ \\
\hline
\end{tabular}

Mplus Version 8.3 Commercial/Non-Profit/Government Pricing

\begin{tabular}{l|c|}
\hline Mplus Version 8.3 Products & $\begin{array}{c}\text { Version 8.3 Pricing For New } \\
\text { Licencees }\end{array}$ \\
\hline Mplus Base Program & $\$ 695$ \\
\hline Mplus Base Program and Mixture Add-On & $\$ 895$ \\
\hline Mplus Base Program and Multilevel Add-On & $\$ 895$ \\
\hline Mplus Base Program and Combination Add-On & $\$ 1095$ \\
\hline
\end{tabular}

Link: https://www.statmodel.com/pricing.shtml/

6. SAS

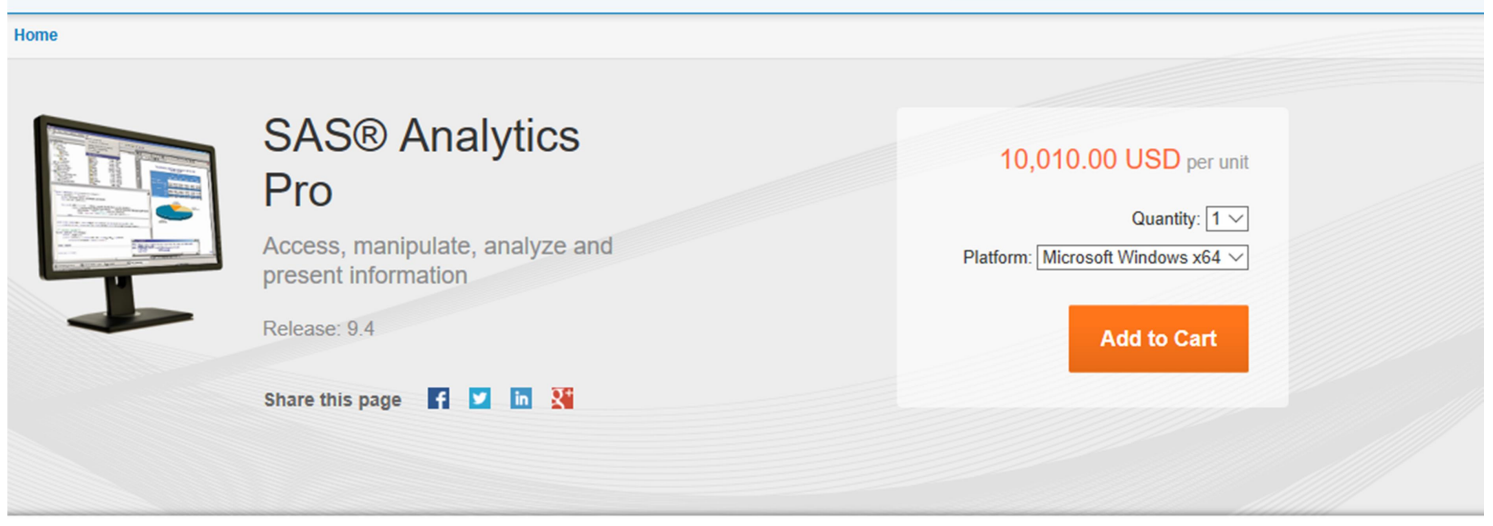

Data Diatas Masih dalam kurs dollar,Jika di Rupiahkan pastinya lebih mahal Teman.

Link:https://www.sas.com/store/products-solutions/sas-analytics-

pro/prodPERSANL.html 